\title{
Improving the quality management of an enterprise in the field of underwater construction
}

\author{
Andrey Plakhin ${ }^{1}$, Igor Semenets ${ }^{2}$, Alexandr Kokovikhin ${ }^{3}$ and Ruslan Dolzhenko ${ }^{3 *}$ \\ ${ }^{1}$ Ural State University of Economics, Department of Management, 8th March str. 62, Ekaterinburg, \\ Russian Federation \\ ${ }^{2}$ Slavonic University of the Republic of Moldova, Department of Economics, Florilor str. 28/1, \\ Chisinau, Moldova \\ ${ }^{3}$ Ural State University of Economics, Department of Labour Economics and Human Resources, 8th \\ March str. 62, Ekaterinburg, Russian Federation
}

\begin{abstract}
Quality management is the basis for achieving the competitive advantages of any enterprise. The article reveals the necessity of research into the problem of quality management with the aim of forming competitive advantages of the enterprise. The authors consider the solution of this problem by the example of an underwater construction enterprise.
\end{abstract}

\section{Introduction}

Competitiveness is one of the main indicators of the state of any enterprise as an economic system that determines the prospects for further development, as well as the possibility of achieving strategic goals. At the same time, as shown by numerous studies, quality management is now becoming the basis for achieving competitive advantages of the enterprise, which is primarily due to the complexity of the structure and content of social and economic processes in the modern world, which largely influences the formation of new requirements for management procedures and technologies, which today define the practice of management organizations.

Requirements and constraints formed by the external environment of organizations prompt them not only to adapt and optimize the business processes applied by companies, but also to improve management technologies and regular management procedures. Therefore, issues that determine the problems of modern quality management are becoming a priority.

The purpose of this study is to develop an economic and mathematical model for assessing the effectiveness of the enterprise's quality management system (QMS) in the field of underwater construction based on the use of the method of additive convolution of partial performance criteria for each process into one and determining the boundaries of the QMS state by the method of fuzzy clustering.

\footnotetext{
*Corresponding author: apla@usue.ru
} 


\section{Methods}

The problem of quality as an economic category arose with the development of social production, with the beginning of the generation of services as a response to the daily needs of people. At present, the survival of any firm, its stable position in the market, is determined by the level of competitiveness, which in turn is related to the indicators of the price level and the level of quality of services.

The quality of services or works should be understood as the beneficial effect received by the consumer as a result of the provision of this service. Clearly, the successful implementation of a quality product to the consumer is the main source of the enterprise's existence. At the same time, quality implies that the services provided meet the expected or established standards. To ensure the necessary level of service quality, enterprises need not only advanced technology, the necessary material resources, qualified personnel, but also rational organization of work, efficient management of the enterprise based on the use of advanced QMS [1].

General issues of quality management were devoted to their work V. I. Gissin, L. E. Basovskiy, J. Bourke, S. Roper [2], V. B. Protasiev, V. Yu. Gulenkov, Y. S. Cho, J. Y. Jung, K. Linderman [3], M. C. Kupriyanova, F. Taddese [4], L. Ilies, H. C. Salagean, I. Beleiu [5], J. M. Wu, X. D. Ling [6], J. Huang, Y. Bian, W. Cai [7] and others. The problems of developing the quality management of the enterprise in various aspects, including for Russian enterprises, were developed in the works of S. P. Konoplev, O. V. Kozhevina, V. M. Mishin and other authors.

Nevertheless, the issues of introduction and improvement of QMS of specialized companies remain in scientific research not fully disclosed. In particular, this article considers the QMS for the enterprise in the field of underwater construction and hydraulic engineering - UralPodvodStroy LLC.

It is quite obvious that the main task of enterprises that produce complex technical, including underwater and diving works on the erection of the underwater part of various structures, is the high quality of these works, which can be ensured as a result of a high degree of organization of work, attracting highly skilled engineering and management personnel, use of advanced standards and QMS.

The QMS should include such functions as:

1. Functions of strategic, tactical and operational control.

2. Functions of decision-making, controlling impacts, analysis and accounting, information and control.

3. Functions are specialized and common for all stages of the product life cycle.

4. Management functions for scientific, technical, industrial, economic and social factors and conditions.

In addition, in our opinion, the QMS must continuously evolve in the company by developing and implementing a set of measures and other continuously implemented operations that ensure the achievement of the required quality of services or products - that which results from the activities of this organization. The most important difference of the QMS from isolated and random actions towards improving product characteristics or preventing production defects is that the operation of the system is not accidental, but systematic and complex, and also leads to the necessary pre-worked consequences.

In order to improve the QMS for the above-mentioned category of companies engaged in underwater construction work, it seems expedient to introduce an economic and mathematical device that allows assessing the quality level of the work performed.

To ensure control and quality management, the manufacturer of the work is desirable to have quantitative characteristics, although this is not always possible, but whenever possible, the requirements put forward by the consumer in the form of qualitative 
characteristics must be translated into their quantitative counterparts. Quality as a set of characteristics of a product / service related to its ability to meet established and perceived needs is multidimensional.

Consider the task of forming parameters for assessing the quality of business processes of the quality management system $\left(R_{b p}\right)$ and the effectiveness of this system $\left(R_{s}\right)$. The object of research was chosen - OOO UralPodvodStroy - an enterprise in the field of underwater construction and hydraulic engineering (Perm, Russia), where QMS has been functioning for 5 years. The calculation of the performance indicators of the quality management system covered the period from 2015 to 2017.

The main parameters of the quality of work for the analyzed company are functional characteristics, reliability - the number of serviceable failures for the service life, durability, defectiveness - the number of defects detected by the customer and a number of others.

In connection with the fact that as a result of using only technical and economic parameters that involve, among other things, studies of a significant amount of data processed, a reliable determination of the effectiveness of the company's business processes as a whole is not provided unambiguously and in full. This circumstance is also due to the different degree of importance of business processes, as well as the importance of the measured parameters or indicators themselves. In this regard, it seems appropriate to use a model based on expert assessment methods using vague categories (odd-set theory).

To this, at the first stage it is proposed to select experts $(\mu)$ taking into account the following requirements:

a) the group of experts should be problem-oriented;

b) the composition of experts should include external auditors and representatives of scientific research organizations;

c) consist of specialists with the highest training (having experience of professional and innovative activity in the same field not less than 5 years, having the appropriate the appropriate education and qualifications).

As the initial data for the work of experts, the significance of individual business processes and their groups should be determined, including:

- the main business processes for the implementation of underwater construction works, $k$-th quality parameters which must be determined for $R_{b p}$, taking into account various regulatory requirements (GOST, TU, SNIPs, etc.);

- auxiliary business processes that implement the supporting functions in relation to the main business processes and are characterized by their technically measurable and qualitative parameters;

- business management processes that determine the general logic and scheme of organization of the company's activities, and implement the basic management functions, the qualitative parameters of which are determined both by internal regulations and by the achievement of the company's objectives in general;

- business development processes implemented within the framework of certain investment projects aimed at increasing the company's economic performance in the long term.

In the process of analyzing the technical and economic indicators of business processes, experts should take into account the planned values of the indicators being evaluated, the best practices of other similar enterprises, statistical data on the results of implementing business processes for previous periods, and other aspects.

At the next step, the task of experts is to evaluate:

- $k$-th quality parameters of the $i$-th business process when performing the $t$-th type of work for the $j$-th customer;

- the effectiveness of business processes to ensure the quality of the work performed. 
When assessing the above parameters, it is sometimes difficult for experts to give any quantitative estimates, so it is suggested to use the concepts of vague categories when the value of a linguistic variable is expressed not by a number but by a word or group of words in a natural language.

In this case, the experts, when answering the questions posed about the assessment of the quality of business processes, it will be quite understandable to operate with such indicators as "very good", "good enough"; "OK"; "satisfactorily"; "almost satisfactory"; "unsatisfactory". To assess the effectiveness of the quality management system in general, it is possible to operate with categories such as "the system does not function", "the system does not work efficiently", "the system functions efficiently, "the results are good", "the results are high, and "the results are excellent".

The estimates obtained from the expert survey for each of the coefficients considered can be represented as two fuzzy sets $A 1$ - characterizes the quality of business processes and $B 1$ - the effectiveness of the company's quality management system.

Fuzzy sets will be sets of pairs of the form $x, \mu(x)$ for the set $A$ (Table 1.) and $y, \mu(y)$ for $B$ (Table 2), where $\mathrm{x} \in \mathrm{X}, \mathrm{y} \in \mathrm{Y} ; \mathrm{x} \rightarrow[0,1] ; \mathrm{y} \rightarrow[0,1]$ is the fuzzy set membership function. Each element $x$ and $y$ is represented by the membership function $\mu(x)$ and $\mu(y)$.

Table 1. The correspondence of the linguistic variable of the odd-numbered membership function to determine the quality of the implementation of business processes.

\begin{tabular}{|c|c|c|c|c|c|c|}
\hline $\begin{array}{c}\text { Name of the } k \text {-th } \\
\text { quality parameter of } \\
\text { the } i \text {-th business } \\
\text { process for the } j \text {-th } \\
\text { customer }\end{array}$ & $\begin{array}{c}\text { Unsatisfac } \\
\text { torily }\end{array}$ & $\begin{array}{c}\text { Almost } \\
\text { satisfactori } \\
\text { ly }\end{array}$ & $\begin{array}{c}\text { Satisfactor } \\
\text { ily }\end{array}$ & Ok & $\begin{array}{c}\text { Good } \\
\text { enough }\end{array}$ & Very good \\
\hline$\mu(x)$ & 0 & 0,2 & 0,4 & 0,6 & 0,8 & 1,0 \\
\hline
\end{tabular}

A fuzzy set should be described by its membership function, which can be used to process the results of an expert survey. Further, the results of the estimates obtained from all experts for a specific question are averaged according to the following formula (compiled by the authors).

$$
\bar{\mu}(x)=\frac{\sum_{i=1}^{n} \mu\left(x_{i t}\right)+\Delta \mu(x)}{n}
$$

Where $\mu\left(x_{i}\right)$ is the aggregate fuzzy set membership function for describing the quality of the implementation of the $i$-th business process within the $t$-th type of work, $\mu$ is the expert opinion, $\Delta \mu(\mathrm{x})=\mu(x)_{\max }-\mu(x)_{\min }$.

Table 2. The correspondence of the linguistic variable of the membership function of an odd set for determining the effectiveness of the company's quality management system.

\begin{tabular}{|c|c|c|c|c|c|c|}
\hline \multirow{2}{*}{$\begin{array}{c}\text { Parameter } \\
\text { name }\end{array}$} & \multicolumn{6}{|c|}{ Quality parameter value } \\
\cline { 2 - 7 } & $\begin{array}{c}\text { The system } \\
\text { does not } \\
\text { function }\end{array}$ & $\begin{array}{c}\text { The system } \\
\text { does not work } \\
\text { efficiently }\end{array}$ & $\begin{array}{c}\text { The system } \\
\text { functions } \\
\text { efficiently }\end{array}$ & $\begin{array}{c}\text { The results } \\
\text { are good }\end{array}$ & $\begin{array}{c}\text { The results } \\
\text { are high }\end{array}$ & $\begin{array}{c}\text { The results } \\
\text { are } \\
\text { excellent }\end{array}$ \\
\hline$\mu(y)$ & 0 & 0,2 & 0,4 & 0,6 & 0,8 & 1,0 \\
\hline
\end{tabular}

The cumulative fuzzy set membership function for describing the effectiveness of the quality management system can be represented by the formula (compiled by the authors):

$$
\bar{\mu}(y)=\frac{\sum_{i=1}^{n} \mu\left(y_{i}\right)+\Delta \mu(y)}{n}
$$


Where $\mu\left(y_{i}\right)$ is the aggregate fuzzy set membership function for describing the effectiveness of the quality management system with respect to the implementation of the $i$ the business process, $\mu$ is the expert opinion, $\Delta \mu(y)=\mu(y) \max -\mu(y) \min$.

\section{Results}

To calculate the integral measure of the effectiveness of the quality management system of the analyzed enterprise, the coefficients of significance of the four fundamental groups of business processes and each process in the group were determined on the basis of the peer review method, as well as the corresponding assessment of the quality of the implementation of business processes and the achieved level of effectiveness of the quality management system in relation to analyzed business processes, the results of calculations are presented in Table 3 and in Figure 1.

The consistency of opinions of experts was evaluated through the coefficient of concordance of J. Kendall. For process groups, it was 0.92 , and for individual business processes 0.89 , for assessing the quality of business processes 0.91 , for assessing the effectiveness of the quality management system - 0.9.

Table 3. Estimated importance of the importance of individual business processes, the importance of process groups, the quality of implementation of business processes and the quality management system.

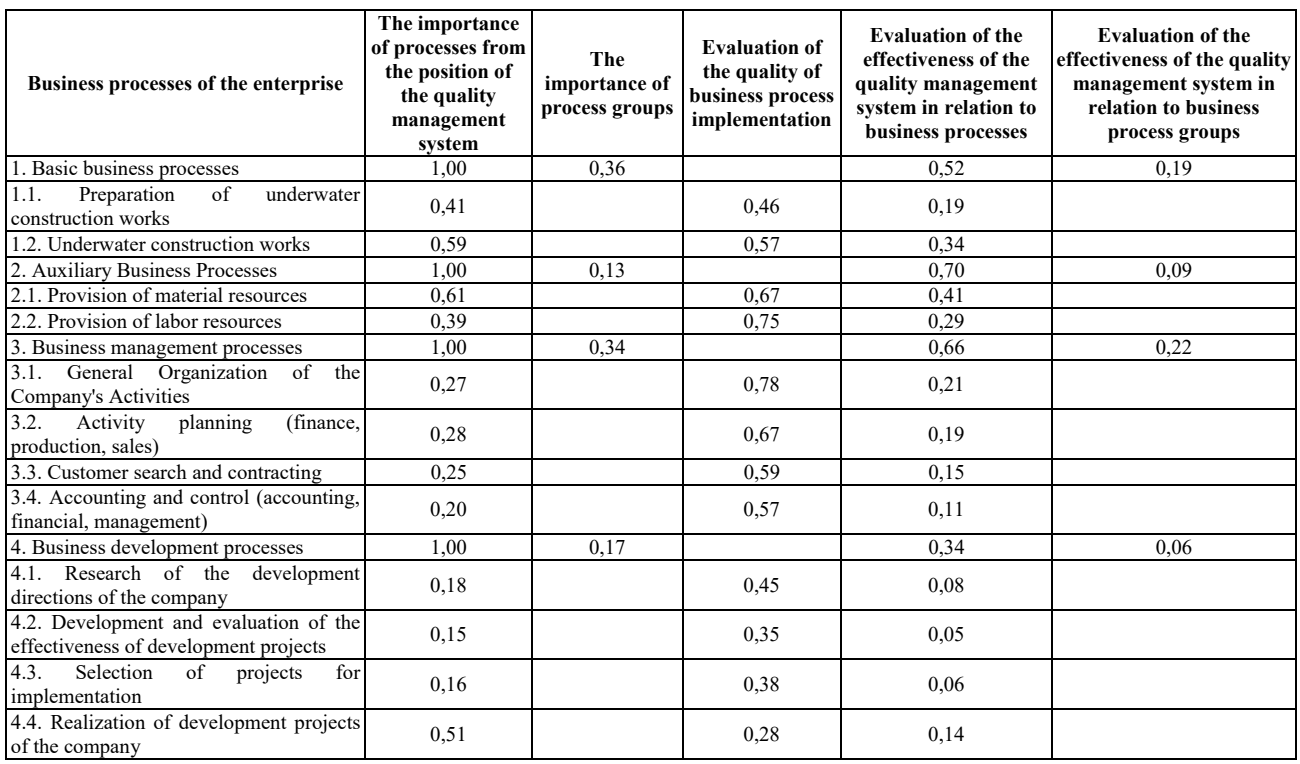

The analysis showed that the company's quality management system ensures the highest effectiveness in achieving the quality of implementation of auxiliary business processes, including the provision of material resources. A high degree of achievement of effectiveness is noted by experts when assessing business management processes.

The worst results of the assessment of both the quality of the processes themselves and the effectiveness of the company's quality management system in relation to them are noted for business development processes. 


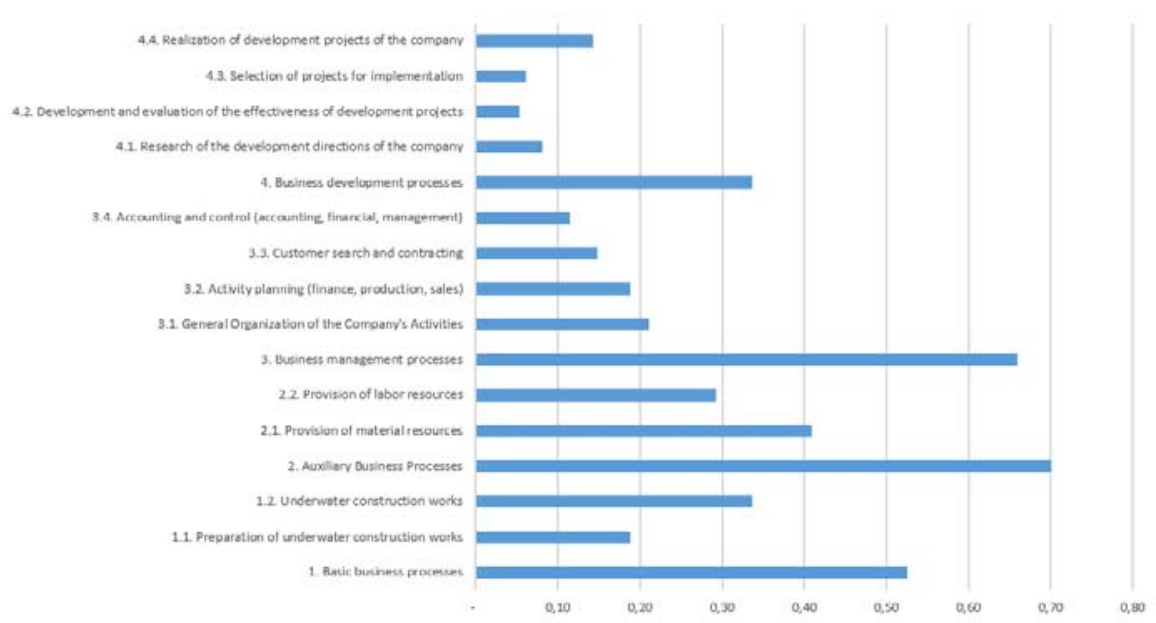

Fig. 1. Evaluation of the effectiveness of the quality management system in relation to the company's business processes.

\section{Discussions and conclusions}

Thus, it is possible to draw conclusions about the effectiveness of the company's quality management system and determine the direction of its improvement, including identifying business processes that require priority measures to improve efficiency. The received parameters can be normalized and further used at the analysis of the reasons of performance of certain works of insufficient quality level and acceptance of administrative decisions on updating of business processes of a quality management system of the company as a whole.

The presented methodology can be used in other enterprises that need special quality requirements for the work performed. Further research on the application of the theory of fuzzy sets in relation to quality management should be aimed at improving the selection criteria for the evaluation of certain business processes, as well as the formation of appropriate guidelines for experts participating in the evaluation work and the company's specialists.

\section{References}

1. A.N. Schmeleva, Qual. Acc. Suc., 18 (160), 100 (2017)

2. J. Bourke, S. Roper, Res. Pol. 46 (8), 1505 (2017)

3. Y.S. Cho, J.Y. Jung, K. Linderman, Int. J. Prod. Ec. 191, 233 (2017)

4. F. Taddese, Int. J. Inn. Tech. Man.14 (4), 1750020 (2017)

5. L. Ilies, H.C. Salagean, I. Beleiu, Amf. Ec. 19 (SE 11), 1050 (2017)

6. J.M. Wu, X.D. Ling, ICFMD-Hong Kong, I, II, 371 (2015)

7. J. Huang, Y. Bian, W. Cai, ICQRRMSE, I-IV, 1283 (2013) 